\title{
La presencia de un gobernador incaico en el valle del Mapocho. La estatuilla antropomorfa del «orejón» incaico de la capacocha del cerro El Plomo
}

\section{Presence of an Inca Governor in the Mapocho Valley. The Anthropomor- phic Figure of the Inca "Orejón» of the Capacocha Cerro El Plomo}

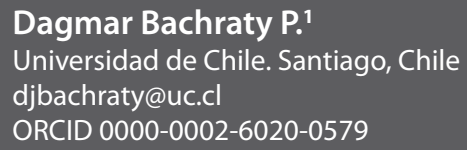

Citar como: Bachraty, D. (2021). La presencia de un gobernador incaico en el valle del Mapocho. La estatuilla antropomorfa del «orejón» incaico de la capacocha del cerro El Plomo. Desde el Sur, 13(2), e0022.

\section{RESUMEN}

Con esta investigación se pretende fundamentar la presencia política de un gobernador incaico en el valle del Mapocho, mediante un análisis multidisciplinario destinado al estudio del dominio inca en la zona y el significado material y simbólico de la estatuilla antropomorfa masculina del «orejón» encontrada en 1988 en la cumbre del cerro El Plomo. La discusión se centra en la crónica de Gerónimo de Bibar y las Cartas de Pedro de Valdivia, principalmente, con el objetivo de destacar la problemática territorial incaica y los posibles rasgos urbanos y simbólicos existentes dentro de los valles Aconcagua y Mapocho. Para ello, hay una aproximación desde la perspectiva etnohistórica de la información y antropológica de la materialidad y el simbolismo de las huacas o hitos demarcatorios, entendidos como mojones territoriales dentro de la ideología incaica. De esta manera, se permite teorizar acerca del posible carácter de «huaca social» de la estatuilla del «orejón».

\footnotetext{
1 Licenciada en Historia, magíster en Estéticas Americanas de la Pontificia Universidad Católica de Chile, y doctora (c) en Estudios Latinoamericanos de la Universidad de Chile (Beca Conicyt). Dentro de sus áreas de interés académico destacan las líneas de investigación etnohistóricas, antropológicas y estéticas, centradas en la simbología de los textiles y su utilización ritual, a través del estudio de la cosmología, la política y economía andinas, principalmente del Tawantinsuyu. Actualmente, investiga la Capacocha del cerro El Plomo y el paso del Inka por el valle del Mapocho (Santiago de Chile).
} 


\section{PALABRAS CLAVE}

Tocrocriq, valle del Mapocho, cerro El Plomo, hitos simbólicos

\section{ABSTRACT}

This research aims to substantiate the politics presence of an Inca governor in the Mapocho valley through a multidisciplinary analysis aimed at the study of the Inca domain in the area and the material and symbolic meaning of the male anthropomorphic statuette of the «orejón» found in 1988 at the top of Cerro El Plomo. The discussion focuses on the chronicle of Gerónimo de Bibar and the Letters of Pedro de Valdivia, mainly, with the objective of highlighting the Inca territorial problems and the possible urban and symbolic features in the Aconcagua and Mapocho valleys. Approaching for this from the ethnohistorical and anthropological information perspective of the materiality and symbolism of the huacas or demarcation landmarks, understood as territorial landmarks within the Inca ideology. Allowing himself to theorize about the possible character of «social huaca» of the «orejón» statuette.

\section{KEYWORDS}

Tocrocriq, Mapocho valley, El Plomo hill, symbolic landmarks

\section{Introducción}

El estudio de la capacocha², celebrada en el cerro El Plomo bajo dominio incaico del valle del Mapocho, posee una serie de problemas y vacíos investigativos derivados de su hallazgo. En 1954, un grupo de «buscadores de tesoros» subieron a la cumbre del macizo andino (5400 metros sobre el mar) para escudriñar en la llamada "pirca de indios $»^{3}$, y encontraron en ella el cuerpo de un niño en perfecto estado de conservación. Con anterioridad a ello, entre 1922 y 1929, Guillermo Chacón subió hasta la cumbre de

2 La capacocha es una ceremonia incaica con características políticas, económicas, sociales y religiosas. Existen casos arqueológicos con sacrificios humanos y sin ellos localizados principalmente en altas cumbres, islas y centros ceremoniales. Dicha complejidad ha llevado a los especialistas a señalarla como el ritual más importante y complejo desde el punto de vista ceremonial, así como político-organizativo.

3 El significado de pirca se relaciona con una construcción de piedra. La pirca principalmente alude a la construcción o deslinde efectuado por una muralla hecha en piedra. Por lo mismo, los primeros excursionistas que ascendieron al cerro El Plomo nombraron a las construcciones allí encontradas como «pirca de indios», debido a que presumieron que dichas edificaciones tendrían relación con un pueblo prehispánico (Cabeza, 1986). 
El Plomo y halló tres construcciones rectangulares hechas de piedra que le hicieron pensar que algo "valioso» podría estar enterrado bajo ellas. En dichas oportunidades, según relató el mismo Chacón, encontró diversos objetos, entre ellos, «siete figuritas» (Ríos, 2009, p. 28). Este «tesoro» le hizo volver recurrentemente al cerro El Plomo, hasta que en 1954, junto con Luis Ríos y Jaime Ríos, hallaron enterrado en la pirca mayor, conocida posteriormente como "enterratorio», el cuerpo de un niño acompañado de una estatuilla de oro con forma de llama, otra de spondylus, una figura femenina de plata con su atuendo completo, una chuspa de plumas con hojas de coca en su interior y tres bolsitas de escroto de llama que contenían cabello humano, uñas y dientes de leche. Por otra parte, y aludiendo a la posibilidad de que Chacón no haya sido el primero en hurgar en la cima, se sabe que en 1896 un grupo de andinistas alemanes señalaron la existencia de ruinas indígenas con indicios de saqueo.

En 1988 los andinistas Sergio Kunstmann y Ludwig Krahl, acompañados de un grupo de especialistas, realizaron una expedición al cerro El Plomo y encontraron una estatuilla masculina con su vestimenta completa, la cual, por la característica de sus orejas horadadas, es conocida como el «orejón». Esta estatuilla fue encontrada en la pirca oeste, junto a restos de tierra con pigmentos de colores, restos de carbón y paja, fragmentos de conchas del tipo Spondylus princeps (mullu), bolsitas con semillas, pequeños maderos y una pequeña placa de oro. Gracias a la descripción del arqueólogo Ángel Cabeza (1988), se obtuvieron los primeros detalles de la figura en cuestión: una estatuilla de plata-oro que representaba a un «orejón inca» con su vestimenta completa, un peso total de 16,2 gramos, $65 \mathrm{~mm}$ de alto; camisa o unku; bolsa para la coca o chuspa; manta exterior o yacolla; cinturón; tocado de plumas conformado por un soporte de madera, insignia o emblema, cordelito de amarre, cuenta de concha spondylus y barbiquejo (Cabeza, 1988, p. 77).

El presente artículo tiene como propósito la consecución del estudio realizado al ajuar del Niño de El Plomo, gracias a una pasantía de investigación dentro del Museo Nacional de Historia Natural de Chile (MNHN). Además, se pretende poner en discusión el significado de la estatuilla masculina dentro del contexto ritual denominado capacocha, y sus posibles ámbitos político-territoriales y simbólicos dentro del valle del Mapocho. Respecto del tema, ya se han presentado y publicado los primeros avances en torno al estudio simbólico y etnohistórico de la estatuilla antropomorfa femenina que acompaña al ajuar del Niño. Por lo mismo, nuestro interés radica en continuar dicha investigación desde una perspectiva multidisciplinaria, la cual incluya la revisión de crónicas tempranas que aporten a la discusión acerca de la presencia de una autoridad incaica 
dentro del valle del Mapocho y otros hallazgos arqueológicos. Asimismo, desde la antropología simbólica y las implicancias sociales relacionadas con la construcción inca del paisaje, se pretende una aproximación a la existencia de dispositivos de poder como ejes marcatorios de dominio directo e indirecto. En este sentido, el estudio material y simbólico de la estatuilla masculina permite un acercamiento al rol político de un «orejón» incaico y las particularidades provinciales de las huacas y sus funciones.

\section{Particularidades etnohistóricas. El Santiago prehispánico bajo dominio incaico y la presencia un gobernador llamado Quilicanta}

Dentro de las crónicas tempranas que señalan la existencia de un gobernador incaico en el valle del Mapocho, Gerónimo de Bibar (1558) nos relata, desde su vivencia y la de sus compañeros de ruta, detalles importantes acerca de la conquista española del «Reino de Chile» y la existencia de autoridades locales e incaicas dentro del valle Central. Asimismo, describe, de manera muy completa, aspectos geográficos que podrían tener conexión con los recursos naturales necesarios para llevar a cabo la empresa hispana. En este sentido, en el capítulo XXVI, se mencionan variados aspectos geográficos del valle del Aconcagua y «las cosas que hay en él». Asimismo, señala el orden político local relacionado con dos «señores de este valle. Sus nombres son estos: el uno Tanjalongo; deste manda de la mitad del valle a la mar; el otro cacique se dice Michimalongo» (Bibar, 1966 [1558], p. 38).

Respecto del nombre de los jefes locales del valle del Aconcagua, estos seguramente habrían pertenecido a etnias mapuches localizadas al norte de lo que hoy geográficamente no se reconoce como tradicional mapuche (Bachraty, 2020, p. 84). Por otra parte, de acuerdo con la descripción de Bibar, es posible visibilizar un orden político dual del territorio, semejante al Hanan y Hurin incaico, pero se dificulta precisar si este orden habría sido introducido por el inca, o si esta división político-social habría existido antes de su invasión. Sin embargo, debido a estudios de la cerámica Aconcagua (Sánchez y Massone, 1995; Brunet, 2014), es posible distinguir la existencia de elementos culturales propios que señalarían una estructura de pensamiento conformada por ámbitos duales y cuatripartitos, además de la existencia de una concepción trinitaria dentro de la conformación del llamado trinacrio.

Se indica que el valle del Mapocho se localiza a 12 leguas del valle del Aconcagua, posee un río que lo cruza y «una pequeña llanura entre la cordillera nevada y otra cordillera de pequeñas sierras que van cercanas a la mar» (Bibar, 1966 [1558], p. 38). Esta descripción de Bibar, apegada a ámbitos geográficos del valle, no señala ningún tipo de edificación del 
tipo incaico o local, sino, más bien, alude a características concernientes a su habitabilidad y clima. No obstante dicho relato, en páginas anteriores menciona el arribo del «general» (Pedro de Valdivia) y su estadía de observación del valle del Mapocho, e indica que Valdivia se habría informado del lugar donde se asentaban los señores del valle, «porque bien sabía que había mucha gente y que era belicosa y guerrera». Además, agrega una disputa entre un cacique del valle del Aconcagua llamado Michamalongo y otro cacique de nombre Antepudo (Bibar, 1966 [1558], p. 35). Entonces, ¿dónde habría vivido esa numerosa gente belicosa? Asimismo, se informa que cuando Pedro de Valdivia entró al valle del Mapocho, los indios corrieron al verlo hacia «carrizales y acequias» del «camino», y les indica que debían avisar al «cacique Atepudo que él venía en el nombre del Apo de Castilla» (Bibar 1966 [1558], p. 35). Al detenernos brevemente en el significado político de la palabra apo, el diccionario de González Holguín (1607) señala que apu en quechua significa «señor grande, juez superior o curaca principal» (p. 23), gobernador de algo, el que provee (p. 165). Por lo mismo, ha de considerarse que cuando Pedro de Valdivia se dirigió a aquellos indios, estos entenderían el significado en quechua y rol de un «apo», ya sea mediante sus palabras o mediada por la traducción efectuada por el lenguaraz que llevaba. Desde esta premisa, es posible conjeturar que en el valle existiría un curaca o jefe con dichas particularidades políticas, o que por lo menos los indios conocerían el significado de la palabra, con la cual Valdivia le daba al rey de España la misma calidad y atribución de un «gran señor» como el «inga» sobre esas tierras. Esa lógica le daría a Valdivia la calidad de jefe local, puesto que «los conquistadores incas y españoles del Qollasuyu integraron las diversas formas de establecer la propiedad privada y la territorialidad modificándolas en su beneficio» (Parisii, 2000, citado por Sotomayor y Stehberg, 2011, p. 188).

En cuanto a la autoridad incaica en el valle del Mapocho, Bibar (1558) señala frente a la prerrogativa de Valdivia y la concertación de un encuentro entre los jefes locales y él mismo, que estos

vinieron de paz el cacique Quilicanta y el otro cacique que arriba dijimos que se dice Atepudo. Estos caciques hacían la guerra a un cacique Michimalongo. Antes que nosotros entrásemos en la tierra tenían gran diferencia entre estos cuatro señores. Vinieron otros once caciques de la comarca, los más cercanos que eran amigos y allegados de aquellos dos caciques, mayormente del Quilicanta. Por ser valeroso y ser uno de los Incas del Pirú estaba puesto por el Inca en esta tierra por gobernador, y estando este Inca en esta tierra cuando vino el adelantado don Diego de Almagro y él le sirviese y se le diese por amigo (Bibar,1966 [1558], p. 39; las negritas son mías). 
Referente a esta importante cita concerniente al estado político y territorial del valle del Mapocho, es posible inferir que, a pesar del conflicto entre los jefes étnicos, existe una relación política entre los valles de Aconcagua y Mapocho mediada por el poder inca. Esta misma relación se habría puesto tensa debido a la presencia de Diego de Almagro (1536) y su cercanía con Quilicanta, quien posiblemente habría entrado en conversaciones diplomáticas mediadas por la presencia del inca Paulo, hermano de Huáscar, quien acompañaba a Almagro. Este aspecto político podría haber desestabilizado el poder de Michimalongo en la zona. Según la información de Bibar, Quilicanta habría sido el jefe principal junto a «once caciques de la comarca», quienes se habrían mudado al valle del Mapocho debido a las hostilidades de Michimalongo (Bibar, 1966 [1558], p. 39). Esta información no hace alusión a algún grado de hostilidad local vinculada a la movilidad territorial inca hacia el valle del Mapocho y la consolidación de su poder en la zona. Creemos que posiblemente existía un avance territorial incaico previo al traslado de Quilicanta al valle del Mapocho, debido a que la conexión entre ambos valles residiría en el tránsito de personas y productos hacia el sur. A propósito de este tema, John Hyslop (1998) hipotetiza respecto de la existencia de diversos tipos de fronteras incaicas, definidas en torno al grado de subyugación y penetración de las instituciones estatales, puesto que algunos pueblos bien podrían haber guardado algún tipo de lealtad simbólica, y mantenido ciertas libertades dentro del ámbito político y económico (p. 33).

La importancia en la constatación del dominio inca sobre el territorio y la relación existente frente a la adjudicación hispana no es posible de establecer bajo las palabras de Pedro de Valdivia, ya que esta presenta constantes omisiones acerca de la presencia incaica en el territorio del valle del Mapocho. En este aspecto, Valdivia en sus cartas no menciona la jurisdicción incaica o nombre de algún representante del inca en dicho territorio, pero deja entrever su conocimiento acerca de los señores de «estas tierras», al señalar que «por un indio que tomé en el camino cuando venía acá, supe que todos los señores desta tierra estaban avisados de Mango Inga, con mensajeros que vinieron delante de mí» (carta a Hernando Pizarro, 1545, p. 55; las negritas son mías). Con ello comenta que los indios tenían la orden dada por el «inga» de esconder el oro y destruir los campos. Esta información permite inferir la existencia de espacios mineros y agrícolas bajo dominio inca, así como la existencia y mantenimiento de un poder local. Al continuar el relato, Valdivia señala que luego de meses viviendo en el valle y al temer una rebelión luego del asentamiento hispano, "atendí a me velar muy bien y andar sobre aviso y a encerrar comida, y metí tanta, que bastaba para nos sustentar dos años, porque 
había grandes sementeras, que es esta tierra fertilísima de comidas» (carta a Hernando Pizarro, 1545, p. 56). Esta información nos hace preguntarnos: ¿quién y cómo habría aumentado la producción agrícola del valle? ¿Dónde guardaría Valdivia la comida para dos años? ¿Él mandó a construir solo una iglesia, casas para sus soldados y otra para él? ¿Existe alguna omisión intencional frente a la existencia de una urbanización incaica?

La hipótesis de un trazado de la ciudad de Santiago y su fundación a partir de una edificación incaica ha sido el gran tema investigativo del arqueólogo Rubén Stehberg y el historiador Gonzalo Sotomayor, quienes señalan la mención de «un tambo grande que está junto a la plaza de la ciudad» $(2012$, p. 87) en un documento en las Actas del Cabildo de Santiago, fechado el 10 de junio de 1541. Respecto de dicha construcción, existe la duda de si este tambo tuvo carácter prehispánico o fue construido por los españoles. Según descripciones hispanas, un tambo sería una "casa común de juntas o juzgado» (González Holguín, 1607, p. 284) o, en su defecto, un lugar donde se acopia la comida y la contribución del pueblo (González Holguín, 1607, p. 133; las negritas son mías). Este lugar, el tambo grande, habría sido el lugar donde Pedro de Valdivia fue elegido como gobernador de Chile, y donde el procurador Antonio de Pastrana habría llamado a reunión mediante un pregonero y el tañer de una campana, «porque no había otra mayor, para que al sonido de ella, como era costumbre, se juntase todo el pueblo y común en un tambo grande que está junto a la plaza de la ciudad» (Actas del Cabildo de Santiago, 1861, citadas por Stehberg y Sotomayor, 2012, p. 106).

Concerniente a este tambo, como hicimos notar en el párrafo anterior, sería posiblemente el lugar donde Valdivia habría acopiado la comida para «dos años», puesto que ese recinto, debido a su ubicación, sería un lugar seguro, seco, de buen tamaño y a distancia prudente de vigilancia para guardar tan importante recurso. Por lo mismo, si sus hombres estaban a cargo de alguna insurgencia y los indios a disposición recolectando comida y construyendo, como él mismo menciona al señalar que «hiciesen casas primeramente para Santa María y para los cristianos que conmigo venían y para mí» dentro del trazado indicado (carta a Hernando Pizarro, 1545, p. 55), posibilita inferir que el trazado urbano que él mismo señala, así como el uso de sementeras y el tambo grande que se usaba como punto de congregación, hayan existido previamente. Por otra parte, sobre el trazado urbano español, es sabido que la ciudad de Santiago fue fundada en verano el 12 de febrero de 1541, fecha que coincide con el tiempo de las cosechas tardías. Considerando este hecho fundacional del dominio español, la preocupación primaria debió ser la recolección de alimentos para el invierno, aspecto que redunda en la utilización y existencia 
de infraestructura y recursos locales. Esta urbanización prehispánica del valle del Mapocho podría ser ratificada gracias al trabajo arqueológico de Rubén Stehberg, que en 2017 encontró debajo del actual Museo Nacional de Historia, localizado al frente de la plaza de Armas de Santiago, una serie de sistemas de canalizaciones que habrían llevado agua del río Mapocho al centro de un asentamiento incaico ${ }^{4}$. Gracias a este hallazgo, se pudo comprobar la existencia de «canales y acequias de regadío, que conformaban una red de predios agrícolas de producción excedentaria destinada a consolidar la conquista incaica en la frontera meridional del imperio» (Stehberg y Morales, 1987, citados por Stehberg y Sotomayor, 2012, p. 89).

La existencia de canalizaciones más allá de su aspecto técnico y tributario agrícola puede ser analizada como una sacralización del paisaje mediante la circulación del agua y el asentamiento ideológico del poder incaico. En este sentido, creemos que el pensamiento andino posee una característica cultural asociada al rol y fertilización de la tierra mediante el elemento distintivo del fluido, ya sea este agua, sangre o semen. Los vínculos existentes entre estas relaciones hipostáticas de pensamiento se encontrarían contenidas en sus mitos, los cuales señalan aspectos civilizatorios concernientes a personajes dioses o, como señala Rebeca Carrión (2005), a un desarrollo agrícola basado en la construcción de obras hidráulicas ejecutadas por un dios en particular (p. 121). Por ello, los espacios demarcados mediante canalizaciones y flujos de agua simbolizarían espacios de fertilidad vinculados a una ideología de poder, al ritualizar el paisaje como señal territorial y civilizatoria, dirigida, a su vez, por la presencia política de un gobernador incaico.

En torno a estos ámbitos ideológicos, según Luis Cornejo y Miguel Saavedra (2018), las hipótesis respecto del dominio militarista inca en la zona han ido variando hacia el análisis y la comprensión de las herramientas políticas y simbólicas de dominio (p. 133). Por esto, desde la arqueología existe una reinterpretación del control inca en la zona central de Chile, la cual considera desde la existencia de un centro administrativo hasta el establecimiento de un «Cusco provincial» que habría determinado la matriz urbana de Santiago (Cornejo y Saavedra, 2018, p. 134). Estas propuestas han permitido ampliar el foco de análisis hacia hipótesis que contemplan la importancia no solo ritual de lugares como el adoratorio del cerro El Plomo, cerro San Ramón, cerro Chena o cerro Peladeros, sino también bajo ámbitos funcionales de marcación territorial que habrían incluido no únicamente la participación inca, pues estos mecanismos de eficacia

4 Visité el lugar arqueológico en junio de 2017. 
simbólica debieron contener componentes ideológicos entendibles por todos los participantes. Así, se recuerda que el Niño sacrificado en la capacocha del cerro el Plomo habría sido lupaca (Boletín, 1957-1959, p. 33) y que la importancia del sacrificio humano en torno a la consolidación de alianzas y resolución de conflictos también habría sido practicada por el pueblo mapuche (Goicovich, 2018, p. 432). Por lo mismo, se cree que el inca habría utilizado ámbitos diplomáticos enmarcados bajo la celebración de festividades públicas (Pavlovic et al., 2019, p. 74).

Respecto del trazado de Santiago, estudios de Patricio Bustamante y Ricardo Moyano (2016) indican que la ciudad hispana se habría construido sobre el diseño inca, ya que el patrón de damero habría seguido el tamaño de una haukaypata inca (p. 179). Esta última se habría localizado en la actual plaza de Armas de la ciudad. Frente a ella, en su costado oeste, existe un templo inca (hoy, catedral de Santiago) y en su costado norte, siguiendo el Camino Inca, los paredones de la «Casa del Inga» y un tambo (Bustamante y Moyano, 2016, p. 178).

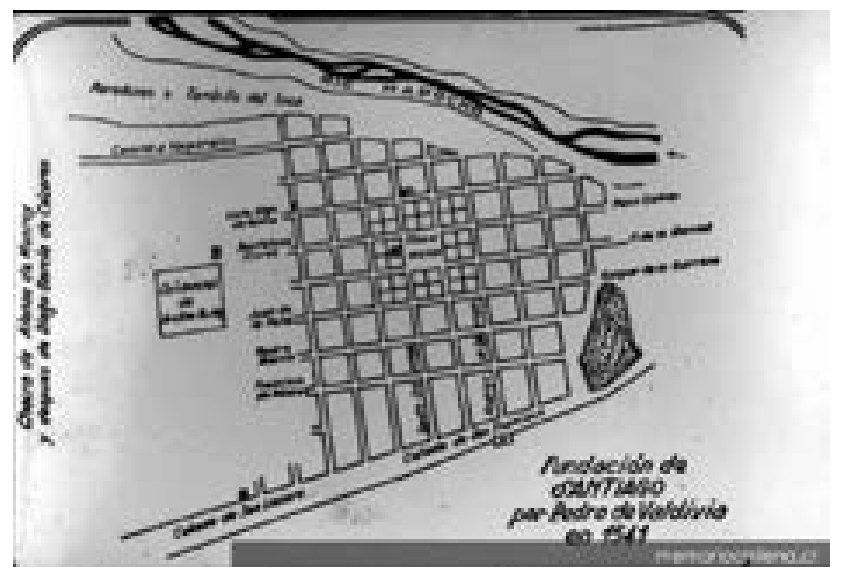

FIGURA 1. Mapa 1500-1554. Edición desconocida, 1900. Colección Biblioteca Nacional de Chile ${ }^{5}$

\section{El «orejón» incaico. Un testigo material y simbólico del poder incaico}

Los hallazgos arqueológicos del cerro La Cruz, localizado en la ribera norte del río Aconcagua, podrían ratificar el relato de Bibar (1558), respecto de la presencia cusqueña en dicho valle, así como muchos otros hallazgos sobre la posible existencia de un punto administrativo en la zona. 
Este cerro en cuestión posee una característica rocosa, una orientación proyectada hacia el norte, posibles plataformas ceremoniales, restos de «hachas de cobre, láminas de plata, pequeños cinceles, punzones de sección cuadrangular, aros de doble espiral de cobre y una campanilla plegada de cobre» (Martínez, 2011, p. 15), y restos cerámicos e inca locales. Los hallazgos posibilitan asociar esta materialidad a la presencia de alguna autoridad cusqueña y a la celebración y consagración de hitos demarcatorios relacionados con lugares de altura. De hecho, Andrea Martínez (2011) sostiene el posible vínculo de estos hallazgos con las festividades del Cápac Raymi y Cápac Quilla: la primera ceremonia estaría asociada a la iniciación de muchachos (orejones) y la segunda, a la preparación de la tierra para el cultivo según el calendario ritual incaico (p. 113).

Referente a ello, la presencia de orejones incas y su participación dentro de rituales está visible en la alusión que realiza Guaman Poma de Ayala (1615) frente a la presencia de un tocricroq en la celebración de una capacocha u otro rito de tipo sacrificial:

Y de todo ello les dauan cuenta y rrelación al dicho Ynga y lo hacían estos dichos sacrificios en presencia de los corregidores tocricoc $\mathbf{b}$ y de los jueses michoc yngas. Éstos enbiaua por la posta y chasque [postillón] a la cauesa deste rreyno abisar de lo que pasa del sacrificio (Guaman Poma de Ayala, 1615, p. 273; las negritas son mías).

Este «corregidor» habría poseído la categoría de gobernador o michoc, es decir, un juez provincial. Sin embargo, Guaman Poma (1615) agrega que los jefes étnicos locales habrían guardado sus privilegios, puesto que «la casta de ellos les enbía a ser corregidor en las prouincias y no auía tiniente, cino los mismos principales de cada prouincia, como dicho tengo» (p. 349). Esta información política podría servir de orientación para el análisis de los lazos existentes entre Michimalongo y su dominio sobre el valle del Aconcagua y el traslado de Quilicanta al valle del Mapocho, como sostiene Bibar (1558). Por lo mismo, Michimalongo habría tenido la soberanía suficiente como para desplazar al jefe inca. Por otra parte, estos gobernadores o «corregidores» de «orejas alargadas» habrían sido elegidos y distinguidos, donde «a los buenos y sanos les ocupaua en guerra y batalla y otros seruicios de bueno y de sano» (Guaman Poma de Ayala, 1615, p. 349). A pesar de las hipótesis de pactos diplomáticos, este aspecto podría indicar el rol militar del jefe provincial inca.

En cuanto a las manifestaciones ideológicas como estrategia de dominio, amplios son los estudios sobre el establecimiento de particularidades simbólicas y rituales como mecanismos de demarcación territorial incaicas, entre ellas la capacocha (Mignone, 2009; Molinié, 2010; Afik, 2015; 
Uribe y Sánchez, 2016). Pablo Mignone (2009) señala que esta importante ceremonia del culto solar y el creador estaba directamente vinculada con la ratificación del poder inca y su linaje, mediante la articulación de «dispositivos rituales que se entienden como intervenciones necesarias para la acción de los hombres con otros hombres» (p. 58). Esta particularidad ritual visualizada a través del despliegue de poder en el espacio territorial permite teorizar acerca de un dominio basado en manifestaciones ideográficas o simbólicas, que conformarían espacios de interdigitación (Martínez, 1998).

Referente al aspecto ideográfico, existe una referencia pictográfica de un dignatario incaico en la zona meridional, entre el valle de Aconcagua y el Mapocho. De hecho, Stehberg (2012) y José Berenguer (2013) han establecido que este dibujo podría manifestar efectos marcatorios en áreas de distinción geográfica como el cordón de Chacabuco, donde se encuentra la pictografía. La sacralización del poder mediante la elección de espacios del paisaje que articulan un territorio podría estar vinculada a los significados de la vestimenta de este dibujo. Este petroglifo de forma antropomorfa presenta una túnica ajedrezada con una hilera de rombos y dos triángulos en sus extremos. Para Berenguer (2013), esta representación con casillas de tablero de ajedrez se vincula a la túnica que utilizaba el ejército incaico (p. 336). Es decir, a ámbitos de poder de un sistema de orden.

Estas representaciones ideográficas, como la túnica ajedrezada, podrían manifestar espacios de transición más que de servidumbre, como estipula Berenguer (2013), debido a que su ubicación podría establecer bisagras de paso entre el dominio de un valle al otro. En este sentido, como sugieren Sotomayor y Stehberg (2011), «es significativo que los Inkas de Perú se adjudiquen tierras para sí en el valle de Aconcagua, de acuerdo [con] una forma administrativa instaurada por ellos en otras partes del Tawantinsuyu» (p. 184). La particularidad del cordón montañoso de Chacabuco, donde se encuentra la pictografía de este posible personaje del ejército incaico (y cuya vestimenta nos recuerda al unku que viste la estatuilla masculina del cerro El Plomo), separa el curso superior del río Aconcagua del valle del Mapocho. En esta área, existen igualmente restos de un asentamiento diaguita-inca (Berenguer, 2013, p. 318). Por otra parte, el tipo de vestimenta ajedrezada se encuentra no solo en la vestimenta de la figura del cerro El Plomo, sino en una estatuilla hallada en el cerro Las Tórtolas y en una vasija diaguita inca de la zona de Coquimbo (Berenguer, 2013, p. 326). Estas representaciones visuales podrían indicar nomenclaturas estilísticas y simbólicas relacionadas con espacios duales y cuatripartitos de poder como sistema de orden. Por lo mismo, los espacios donde se encontraron estas representaciones podrían representar 
áreas de apertura y cierre simbólico de poder debido a sus particularidades paisajísticas, regímenes de explotación agraria y metalúrgica. Tal vez este petroglifo y su ubicación puedan hablarnos de espacios donde las estrategias de poder directo e indirecto estuvieron caracterizadas por el tránsito y la movilidad política entre un valle y otro, como lo sugiere el vínculo entre Michimalongo y Quilicanta.

Otro importante factor que considerar dentro del análisis reside en el lugar específico donde se encuentra este petroglifo.

La cueva está en una estrecha garganta rocosa de la quebrada Infiernillo, al pie del Cerro del Diablo, una pequeña estribación de la vertiente sur del cordón de Chacabuco. Una cruz metálica, clavada sobre la cima de la pared rocosa izquierda de la quebrada, anuncia desde lejos la ubicación de la cueva (Berenguer, 2013, p. 319).

La ubicación de la pictografía y de las estatuillas enterradas dentro de una cueva o pirca lajada denotaría la particularidad de un «entrar y salir» que podría estar emparentado a espacios primigenios caracterizados por la luminosidad y oscuridad, y a mitos fundantes como el de los hermanos Ayar, quienes salieron de cuevas con el fin de conquistar nuevas tierras. Es decir, al nacimiento o surgimiento de un poder refrendado a través de las manifestaciones lumínicas y el culto solar. En este sentido, y dada la predominancia del color rojo en el petroglifo, y el color blanco-negro de los unkus ajedrezados, podemos establecer la existencia de un lenguaje cromático de las diversas tonalidades de la luz al salir y al ponerse el sol, al igual que el color existente en diversos textiles de culturas serranas, vinculados a ambientes uterinos (Brugnoli et al., 2011, p. 107). La importancia del textil «estatal» y su visualidad estaría asociada al inca, la emanación de su poder y el control productivo de las prendas.

Los famosos uncu (con tocapus) realmente se pueden asociar con los incas o con el Sapa Inca, cuyo conjunto de tocapus prácticamente representaba el imperio. Los incas manipularon esta codificación de tal modo que determinaron quiénes y qué etnias podían llevar qué tipo de vestido y de qué color, con lo cual se puede hablar de un control de la codificación del color (Brugnoli et al., 2011, p. 107).

\section{Revisión iconográfica y simbólica del textil de la estatuilla masculina del «orejón» del cerro El Plomo}

Como hemos expuesto en la investigación de la estatuilla antropomorfa femenina del cerro El Plomo, la presencia de dichas manifestaciones simbólicas estarían asociadas a un aspecto social del Incario y su sistema de pensamiento (Bachraty, 2019, p. 325). Con ello construye el soporte 
del símbolo: la cosa propiamente dicha, que puede ser de distintas clases: natural como un trozo de madera, una piedra, metal o elementos de la naturaleza dotados de una unidad propia que facilita su personalización; un objeto fabricado que asocia varias materialidades; $y$ un objeto tratado desde una materialidad viva (Augé, 1998, p. 30).

La ofrenda realizada en adoratorios de altura bajo la personificación de estatuillas revestidas con particularidades fisonómicas y alhajadas individualmente estaría vinculada a los tres tipos de materialidades mencionados por Augé (1998). Es decir, la ofrenda y su función estarían dimensionadas por la «vida» de la materialidad, el lugar desde donde se extrajo y el culto a dichos espacios. En este sentido, el culto «no es pues, según parece, la idolatría grosera de un objeto material. El fetiche es la morada donde reside el espíritu» (Augé, 1998, p. 22). Desde dicha perspectiva, queremos aludir al componente performativo presente en el poder material de la figura, a la presencia misma dotada significado, al objeto entendido bajo un valor simbólico y operativo de una acción social, al mensaje presente en la representación y materialidad del objeto, y a su uso ritual. Es decir, a un mediador del mundo de los hombres y el de los dioses. Este mensaje estaría dimensionado no solo en su función social, sino en la esfera del ser, puesto que la identidad y la materialidad de su representación se encuentra en todo dispositivo simbólico (Augé, 1998, pp. 138-140).

La presencia material de lo sagrado o la personificación de las estatuillas llevaría implícito el poder del Sapa Inca a través de la caracterización de una vestimenta impregnada material y visualmente de su poder político. Un elegido que represente su poder y el de sus ancestros dentro del rito. El cuestionamiento referido a por qué rituales como la capacocha no presentan estatuillas del mismo Sapa Inca guardaría relación con la función simbólica y celebración de la ceremonia. Según diversas crónicas hispanas, la capacocha celebrada en el Cusco era presidida por el inca y su séquito político, además de la momia de sus predecesores. Las comitivas provenientes de todas partes del Tawantinsuyu habrían traído, según Juan de Betanzos (1551), los niños y niñas destinados al sacrificio, así como los diversos objetos y animales destinados para la ofrenda, que el inca habría sacralizado mediante el toque de su mano y la sangre de una llama blanca. Es decir, el inca y su poder estarían presentes en cada ofrenda y sacrificio. Para Margarita Gentile (1996), la presencia del color rojo-amarillo en los objetos y vestimentas conectadas a una capacocha, así como el significado del oro (amarillo) y spondylus (rojo o rosáceo), representan el culto al sol y simbolismos asociados con la fertilidad. Esta interpretación permite pensar que la instauración de huacas, entendidas como todo aquello portador de lo sagrado, llevaba implícita una acción 
civilizatoria dentro de su función. Este aspecto civilizador es referenciado en el relato de Garcilaso de la Vega (2002 [1609]), quien comenta, frente al avance inca en Chili y la resistencia de los purumaucas, que estos incas «volvieron a enviar nuevos requerimientos de paz y amistad, con grandes protestaciones que hicieron, llamando al Sol y a la Luna, de que no iban a quitarles sus tierras y haciendas, sino a darles manera de vivir de hombres, y a que reconociesen al Sol por su Dios y a su hijo el Inca por su Rey y señor» (p. 377).

La importancia de la instauración de una huaca-objeto demarcatoria y sus representaciones visuales tendría correspondencia, además, con un orden dado por la característica geométrica de los textiles, es decir, en un orden alejado del caos y lo incivilizado. Con ello se aporta un nuevo orden investido simbólicamente a través del uso de un unku ajedrezado y la proyección desde el lugar donde fueron ubicados: un lugar de altura. Desde esta perspectiva, los lugares-huaca también estarían investidos de poder, lo que genera zonas de dominio e intersección territorial, tal como lo sugiere también la cita de Garcilaso, al establecer «que no iban a quitarles sus tierras y haciendas».

Para Antoinette Molinié (2010), las denominaciones y articulaciones espaciales establecidas como huacas cumplen un importante rol social, no solo para los incas, sino para las comunidades locales. Estos «cumplen con una función clasificatoria, pues las posiciones que ocupan en el espacio generan territorios de los cuales resultan ser sus respectivos mojones. Además, se les ofrece cantidad de ritos que estructuran la sociedad» (p. 63). Es decir, hitos simbólicos como la cueva de Chacabuco y el unku ajedrezado "dibujado» en la piedra efectuarían demarcaciones entendidas por las etnias locales. Asimismo, la estatuilla del «orejón» de El Plomo efectuaría una personificación de un poder ancestral, o un ancestro en sí mismo, al determinar y legitimar la presencia del poder incaico en dicho lugar, como lo expone Guaman Poma (1615) al mencionar la presencia de los Tocricroq dentro de una capacocha, así como también la presencia de un dignatario inca dentro del rito de iniciación de orejones que menciona Martínez (2011) en el cerro La Cruz. Se establecieron mediante el reconocimiento o la instauración de una huaca, fronteras agrarias y guerreras (Molinié, 2010, p. 63), al igual que espacios agrarios y mineros. Estas demarcaciones no serían ajenas a las comunidades locales, puesto que para que el poder de las huacas funcione, los incas habrían legitimado para sí mismos espacios sagrados de otros pueblos. No por nada el cerro El Plomo fue conocido como Plomo Rico, debido a su característica minera (Cabeza, 1986, p. 222), que debió ser reconocible por los incas y los grupos locales. 
Sobre la estatuilla, creemos que la figura del orejón poseería funciones simbólicas determinadas a estructurar y demarcar un pensamiento cultural de orden a través del significado de su materialidad. De hecho, esta estatuilla porta un llautu, un tocado de cordones como parte de la pieza de metal, la cual, además de las orejas horadadas, manifiesta un símbolo de subordinación al Incario. Creemos que el porte de estos marcadores de poder legitimarían el orden social y político dentro del valle del Mapocho. Para Mary Frame (2007), la comunicación grafica del textil sería un indicativo del rol y rango en el Incario (p. 11), es decir, un espacio pictórico de poder donde cada personaje estaría posicionado y distinguido a través de su atuendo. "Personajes que visten ropas específicas y adornos o llevan objetos que identifican su función, rango u origen personifican las divisiones sociopolíticas del Imperio» (Frame, 2007, p. 11). En la descripción del textil ajedrezado del «orejón» de El Plomo, se distingue una urdiembre en forma calada y tejido en una sola pieza, con remates en los bordes con hilos de color negro, verde, rojo, amarillo, siguiendo una secuencia no homogénea en el patrón. En la parte superior frontal del pecho se visualiza una forma de chakana de color rojo, donde la cuadrícula inferior ajedrezada podría representar el orden político de los cuatro suyus y una dualidad blanco-negro (luz-oscuridad) de los cuadrados que lo componen. Dicho orden podría estar asociado con una chakana basada en una forma geométrica triangular doble truncada. Según Frame (2007), esta forma estaría vinculada a la región que configuraría la provincia del Collasuyu y su relación primigenia con Tiwanaku (pp. 35-36). De hecho, cabe notar, como lo hemos expresado con anterioridad, que el niño sacrificado sería de esta zona altiplánica.

Los metales de los cuales está hecha la estatuilla son plata y oro, según señala Cabeza (1988, p. 77). Esta materialidad permite conjeturar la introducción ideológica no solo del culto solar, como hemos referido en párrafos anteriores, gracias a los comentarios de Garcilaso (1609), sino también la de la luna. Este simbolismo, manifestado en el poder-luz del oro y la plata, podría referenciar un aspecto más complejo que el tributario, pues «no lo daban los vasallos en tributo al rey, sino que lo presentaban (sin que se lo pidiesen) para servicio y ornato de las casas reales y de las del Sol» (Garcilaso, 2002 [1609], p. 374). A través de esta aleación se configura la dualidad andina de los complementos masculino y femenino presentes en la figura entendida como huaca o mojón territorial y civilizador. 


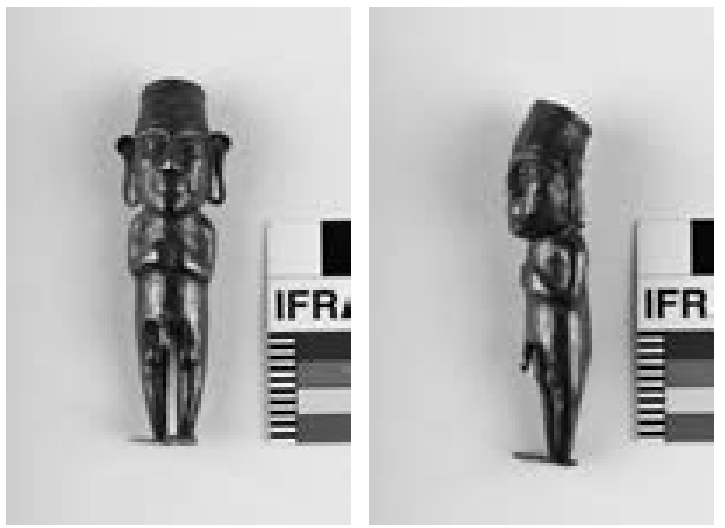

Figuras 2 y 3 . Estatuilla «Orejón del cerro El Plomo». Gentileza del Museo Nacional de Historia Natura, Chile

Respecto del pigmento del color rojo bermellón de la posible chakana truncada del textil ajedrezado, es posible inferir que, debido a su calidad ritual, se conecte con el lugar desde donde se extrajo el color, que dentro de esta investigación se desconoce. Sin embargo, es posible hipotetizar que

El color preferido era el rojo y Acosta habla de las minas de mercurio de Huancavelica, las cuales fueron trabajadas para conseguir el llimpi, el color cinabrio, que se usó para estos fines. También Cobo dice: "Con el llimpi, que es el metal del azogue, solían hacer diversas supersticiones, untándose con él y con otros colores de tierra en tiempo de sus fiestas». Otro color rojo era el llamado ichma, «un color de fruto de árbol que nace en capullo», e ichmakuni significa «embijarse» la cara u otra cosa». Llimpikuni significa igualmente «pintarse la cara con bermellón y embijarse» (Boletín, 1957-1959, p. 32).

Sobre la importancia del pigmento tenemos el relato de Antonio de la Calancha (1638), quien comenta que ishma era sinónimo de llimpi, nombre aplicado al azogue y a su color bermellón, utilizado como maquillaje en diversos rituales. Este color se habría obtenido del fruto de un arbusto llamado ichma y el llimpi, de origen mineral. Asimismo, el cronista sostiene la existencia de un vínculo entre los materiales y la espiritualidad del lugar de extracción, puesto que los indígenas los adoraban besándolos y soplándolos:

Paria es polvos de color colorado, como de bermellón, que traen de las minas de Huancavelica, que es el metal de que se saca el azogue, aunque más parece a zarcon. [...] Usavan los indios que van a minas de plata, de oro o de azogue, adorar los cerros o minas, pidiéndoles metal rico, i para esto velan de noche, beviendo i baylando, sacrificio 
que azen a la riqueza; a los de oro llaman Coya, i al Dios de las minas de plata i a sus metales Mama, i a las piedras de los metales Corpa, adóranlas besando, i lo mesmo al soroche, al azogue i al bermellón del azogue, que llaman Ichma, o Linpi, i es muy preciado para diversas supersticiones (Calancha, 1638, pp. 371-372).

En las citas expuestas se observa una relación entre el carácter de huaca como lugar sagrado y el lugar desde donde se extraen los metales: oro, plata y azogue. Un cerro, mina o arbusto asociado con un mito primigenio, un ancestro-deidad, o una huaca pacarina. Se puede agregar, según Calancha (1638), que el color bermellón en los khipus estaba ligado a asuntos del ejército y a las propiedades del inca. Se desconoce si el análisis químico del color rojo-bermellón en el textil de la estatuilla de El Plomo sería de azogue o cochinilla.

Otra prenda que posee la estatuilla del orejón es la yacolla o manta de color café tierra. Esta prenda de urdiembre calada y tejida también en una pieza presenta remates en sus bordes de color rojo-azul alternada. El tocado cefálico de la figura posee un distintivo penacho de dos plumas color rojo con un adorno de placa metálica que cuelga de él a través de dos hilos. Esta pequeña placa rectangular posee un detalle en su extremo superior de forma circular color rojo. Respecto de los distintivos que ponían en sus cabezas, Pedro Cieza de León (2005 [1553]) comenta que los tocados andinos poseían una identificación visual étnica y señala: «Todos los señores de estos llanos y sus indios traen sus señales en las cabezas, por donde son conocidos los unos y los otros» (p. 178); «traen por señal en la cabeza para ser conocidos de ellos» (p. 208); «Por las cabezas traen todos sus cordones y señales para ser conocidos» (p. 217); «y aunque hubiese juntos cien mil hombres, fácilmente se conocían con las señales que en las cabezas se ponían» (p. 242).

Acerca de los tocados de los capitanes inca, Guaman Poma (1615) menciona que el octavo capitán Apo Camac Inga no posee el tocado con la pequeña placa y su círculo rojo, ni tampoco el unku ajedrezado. Sin embargo, habría sido este

baleroso capitán y que parecía como un león. Tenía temerarios ojos; con una bofetada derriuaua a un hombre y desmayaua ona ora. $Y$ ancí este baleroso capitán fue a Chile lleuando cincoenta mil yndios soldados a la conquista. Y fue hijo de Pachacuti Ynga Yupanqui. Y dizen que mató cien mil chilenos (p. 160; las negritas son mías).

Frente a esta cita, es preciso mencionar que, en el sector donde se emplaza el cerro El Plomo, existe un cordón montañoso llamado Quempo o Cabeza de León, y frente a El Plomo existe otro cerro llamado La Leonera. Al respecto, desconocemos si esta toponimia se relaciona con nombres 
prehispánicos, mas dentro de la disposición comunal y urbana de la ciudad de Santiago aún se conservan nombres atribuibles a jefes étnicos como Vitacura, Huechuraba, Pudahuel, Tobalaba, Ñuñoa, Peñalolén, Maipú, Lampa, Quilicura, etc.

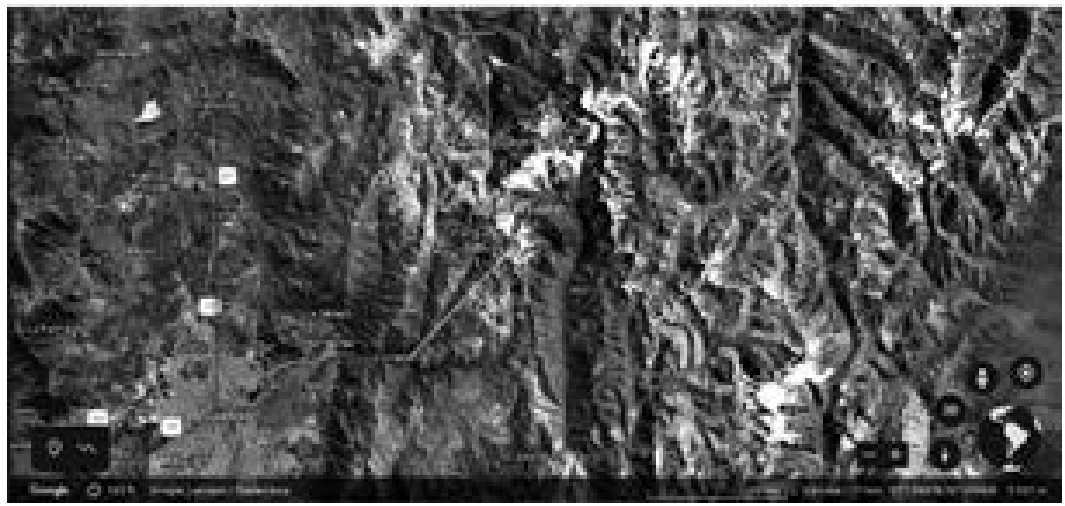

Figura 4. Mapa de Google Earth. Elaboración propia: línea roja, cordón del Quempo desde el cerro El Plomo hasta zona del Alfalfal. Allí se ubican los cerros Capitán Quempo y Teniente Quempo. Línea amariIla: posible ruta entre el cerro El Plomo y zona de Corral Quemado, donde habría existido un tambo inca. Línea azul, trazado del Camino Inca entre la entrada del cordón de Chacabuco y Santiago.

Por otro lado, el cuarto capitán Apo Maitac Inga usa un unku ajedrezado con una terminación en zigzag, un tocado con dos plumas y una pequeña placa con la misma forma que la estatuilla de El Plomo y el pequeño círculo en su parte superior. Este capitán «hizo una destrución y mató muy mucha gente y destruyyó y puso grandes ýdulos y uacas y sacreficios y mandó hazer tenplos de los dioses ýdolos. Y tubo desde la ciudad del Cuzco todo el rreyno del Collau sugeto y amojonado» (Guaman Poma, 1615, p. 152; las negritas son mías).

Por último, dentro de la vestimenta del «orejón» de El Plomo destaca la faja trenzada de color azul y rojo que sujeta por la cintura a la yacolla, y la pequeña chuspa que acompaña al conjunto. Esta última posee franjas verticales de colores rojo, azul y amarillo, con tres franjas que distinguen un motivo de zigzag con volutas a lo largo de ellas. Resalta nuevamente la presencia del color rojo y amarillo, propuesta desde la perspectiva ideológica del culto solar.

Asimismo, dentro de la colección que alberga a la figura del «orejón» dentro del MNHN, existen dos fragmentos de láminas de oro que parecen haber sido parte de un adorno, ya que se encuentran trabajadas y presentan dobleces. También, y como donación de los andinistas Krahl y Kunstmann al museo, existen dos fragmentos de mullu o spondylus que presentan diversas tonalidades de rojizo y rugosidades en su parte superior, que 
indicarían que son pedazos de una concha entera sin trabajar. Se detalla al momento del hallazgo en el informe de Cabeza (1988) lo siguiente:

Dos trozos de concha spondilus que acompañaban como ofrenda la estatuilla, el más grande con un peso de 14,20 [g] y el más pequeño de 8,42 [g]. Dos trozos de láminas de oro y plata de 0,02 a 0,03 mm de espesor dobladas en forma de hacha que también acompañaban como ofrenda a la estatuilla (p. 77).

Los detalles ofrendarios hallados junto a la figura del «orejón de El Plomo» reforzarían aún más la tesis acerca del rol de esta estatuilla como dispositivo simbólico, puesto que su ajuar indicaría la introducción ideológica del culto solar, lunar y el del agua, dimensionado en la presencia de spondylus y el culto a Mamacocha.

\section{Conclusiones}

El hallazgo de una estatuilla antropomorfa masculina, conocida como el «orejón» del cerro El Plomo, nos hace dimensionar la importancia política y simbólica del poder de un dignatario inca dentro del ritual denominado capacocha. La individualización de dicha figura mediante sus características materiales y simbólicas no necesariamente representa al gobernador inca de nombre Quilicanta, mencionado por el cronista Gerónimo de Bibar (1558), sino el establecimiento del poder inca en la zona desde una huaca de altura, como el cerro El Plomo. Dicho aspecto nos hace reflexionar acerca de la importancia ideológica de los marcadores territoriales y sociales dentro de los sistemas de dominio inca en la zona. La configuración de estos marcadores ideológicos, como adoratorios, petroglifos, cuevas y el posicionamiento en altura de una huaca objeto, como la estatuilla masculina, nos hablan de un conjunto de hitos que transforman y legitiman el paisaje. Un mundo ordenado bajo parámetros incas entendibles por los demás agentes políticos. Al respecto, el análisis de dicha estatuilla arroja la existencia de ámbitos simbólico-territoriales de dominio que podrían reafirmar o complementar la teoría arqueológica acerca de un dominio diplomático mediado por la importancia visual de marcadores simbólicos utilizados en festividades y rituales. Sin embargo, la falta de la totalidad del material arqueológico del cerro El Plomo dificulta un estudio más completo.

Dentro del ámbito etnohistórico se ha podido constatar la presencia de un representante inca, el cual habría tenido un rol político atingente a su calidad de apu, señor, tocricoq o gobernador del valle del Mapocho, donde los vacíos presentados por Pedro de Valdivia dentro de sus cartas nos invitan a pensar en la existencia de estrategias de dominación y apropiación de tierras del Sapa Inca a través de la homologación del poder 
castizo con el del Incario. Por otra parte, la urbanización y el asentamiento de la ciudad de Santiago habría sida construida a partir del trazado y edificación local-inca, aprovechando la intensificación de la agricultura y las canalizaciones efectuadas por los incas y la población local, así como el tributo minero.

Los aspectos beligerantes presentados en la crónica de Bibar, referentes a los vínculos entre Michimalongo, señor del valle del Aconcagua, y Quilicanta, en el valle Mapocho, nos hablan de espacios políticos «bisagra» o alternos respecto del tipo de dominación existente en ambos valles. No obstante, la presencia hispana de Diego de Almagro habría fraccionado este sistema de orden hasta la llegada de Pedro de Valdivia. Esta lógica alterna de poder sería visible dentro de la instauración de hitos simbólicos, como las huacas del cerro La Cruz y el cordón del Chacabuco, donde estas habrían ejercido una función mediadora entre un valle y otro, o, como hemos expuesto, bisagras integradoras y delimitadoras que permitirían el establecimiento de relaciones de poder con ciertas particularidades provinciales periféricas; por ejemplo, la existencia de tierras del inca y tierras locales. Sin embargo, se visibilizan a través de estos hitos/ huaca, ámbitos civilizadores que contienen, evidentemente, mecanismos coercitivos que apuntan al establecimiento de un control militar y luego ideológico-diplomático.

\section{Contribución de autoría}

Dagmar Bachraty es autora del artículo y responsable de la estructura y redacción del documento.

\section{Fuente de financiamiento}

Agencia Nacional de Investigación y Desarrollo, ANID (antes CONICYT Chile).

\section{Potenciales conflictos de interés}

Ninguno. 


\section{REFERENCIAS BIBLIOGRÁFICAS}

Afik, B. (2015). Sacrificio humano y reciprocidad: Una ideología de cohesión imperial incaica. Revista Andina, 53, 201-222.

Augé, M. (1998). Dios como objeto. Símbolos, cuerpos, materias, palabras.

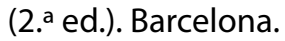

Bachraty, D. (2020). El püron/pron o khipu mapuche. Implicancias simbólicas, usos y posibles aproximaciones históricas y culturales. Revista Chilena de Antropología, 42, 79-94.

Bachraty, D. (2019). La imagen de lo femenino. La estatuilla antropomorfa de la Capacocha del cerro El Plomo. Desde el Sur, 11(2), 317-329.

Boletín Museo Nacional de Historia Natural de Chile (1957-1959), 1(XXVII).

Berenguer, J. (2013). Unkus ajedrezados en el arte rupestre del sur del Tawantinsuyu: ¿La estrecha camiseta de la nueva servidumbre? En M. E. Albeck, M. Ruiz y M. Beatriz Cremonte (Eds.), Las tierras altas del área centro sur andina entre el 1000 y el 1.600 d. C. (pp. 311-352). Editorial EDIUNJu.

Betanzos, J. de (1880 [1551]). Suma y narración de los Incas, que los indios llamaron Capaccuna, que fueron Señores de la ciudad del Cuzco y de todo lo á ella subjeto. Marcos Jiménez de la Espada (Ed.). Biblioteca Virtual Miguel de Cervantes. http://www.cervantesvirtual.com/obra/suma-y-narracionde-los-incas-que-los-indios-llamaron-capaccuna-que-fueron-senoresde-la-ciudad-del-cuzco-y-de-todo-lo-a-ella-subjeto--0/

Bibar, G. (1966 [1558]). Crónica y relación copiosa y verdadera de los Reinos de Chile. Fondo Histórico y Bibliográfico José Toribio Medina.

Brugnoli, P., Jélvez, P. y Hoces de la Guardia, S. (2011). Colores: Un puente entre pasado y presente. Revista Diseña, 3, 106-113. http://www.revistadisena. com/colores-un-puente-entre-pasado-y-presente/

Brunet, A. (2014). Prehistoria Agroalfarera de Chile Central y la llegada de los Incas a este territorio. https://www.academia.edu/26871604/Prehistoria_Agroalfarera_de_Chile_Central_y_la_llegada_de_los_Incas_a_este_ territorio

Bustamante, P. y Moyano, R. (2016). Santiago: Una ciudad con pasado incaico. Orientaciones orográfico-astronómicas y un posible sistema de ceques en los Andes del Collasuyu. Xama, 24-29, 177-190.

Cabeza, Á. (1988). El sacrificio humano en la cordillera de los Andes. El santuario Inca Cerro El Plomo (Chile). https://www.andeshandbook.org/media/documents/2_Cerro_Plomo.pdf

Cabeza, Á. (1986). El Santuario de altura inca del cerro El Plomo. Tesis de grado para optar al título de licenciado en arqueología y prehistoria de Chile. Universidad de Chile. 
Calancha, A. (1638). Chronica moralizada del orden de S. Agustín en el Perú, con sucesos exemplares vistos en esta Monarchia. http://www.cervantesvirtual.com/obra/coronica-moralizada-del-orden-de-san-augustin-en-elperu-con-sucesos-egenplares-en-esta-monarquia-/

Carrión, R. (2005). El culto al agua en el antiguo Perú. (2. ${ }^{\text {a }}$ ed.). Instituto Nacional de Cultura del Perú.

Cieza de León, P. (2005[1553]). Crónica del Perú. El señorío de los incas. Biblioteca Ayacucho.

Cornejo, L. y Saavedra, M. (2018). El centro político Inka en el extremo austral del Tawantinsuyu (Chile Central). Boletín del Museo Chileno de Arte Precolombino, 23(1), 133-158.

Frame, M. (2007). Lo que Guaman Poma nos muestra pero no nos dice del tokapu. Revista Andina, (44), 9-48.

Garcilaso de la Vega, I. (2002 [1609]). Comentarios reales. Agencia Española de Cooperación Internacional.

Gentile, M. (1996). Dimensión sociopolítica y religiosa de la capacocha del cerro Aconcagua. Bulletin de I'Institut Français d'Études Andines, 25(1), 4390.

Goicovich, F. (2018). Un sistema de equivalencias: El ritual del sacrificio en la cultura reche-mapuche de tiempos coloniales (S. XVI-XVII). Historia, 51(2), 423-454.

González Holguín, D. (1842 [1607]). Gramática y arte nueva de la lengua general de todo el Perú: llamada lengua qquichua o lengua del inca. https:// archive.org/details/gramticayartenue00gonz/page/n1/mode/2up

Guaman Poma de, F. (1615). Nueva coronica y buen gobierno. Det Kongelige Bibliotek. http://www.kb.dk/permalink/2006/poma/info/es/frontpage. htm

Hyslop, J. (1998). Las fronteras estatales extremas del Tawantinsuyu. En T. D. Dillehay y P. Netherly (Eds.), La frontera del Estado Inca (pp. 33-51). Fundación Alexander von Humboldt y Editorial Abya Yala.

Martínez, J. L. (1998). Pueblos del chañar y el algarrobo: los atacamas en el siglo XVII. Dibam.

Martínez, A. (2011). Reevaluación del sitio Cerro La Cruz. Su función en las estrategias de dominio incaico en el curso medio del Aconcagua. [Tesis para optar al título de arqueóloga, Universidad de Chile. http://repositorio. uchile.cl/tesis/uchile/2011/cs-martinez_a/pdfAmont/cs-martinez_a.pdf

Mignone, P. (2009). Miniaturas zoomorfas del volcán Llullaillaco y contraste entre régimen estatal y vida comunitaria en la Capacocha. Boletín del Museo Chileno de Arte Precolombino, 1(14), 55-68. 
Molinié, A. (2010). La memoria de los dioses: el rito en la gobernabilidad incaica. Revista Andina, 50, 59-81.

Pavlovic, D., Sánchez, R., Pascual, D., Martínez, A., Cortés, C., Dávila, C. y La Mura, N. (2019). Rituales de la vida y de la muerte: Dinámicas de interacción entre el Tawantinsuyu y las poblaciones locales en la cuenca del Maipo-Mapocho, Chile Central. Estudios Atacameños. Arqueología y Antropología Surandinas, 63, 43-80.

Ríos, L. (2009). El niño inca. La verdadera historia del niño del cerro El Plomo. Pehuén.

Sánchez, R. y Massone, M. (1995). Cultura Aconcagua. Ediciones de la Dirección de Bibliotecas, Archivos y Museos.

Sotomayor, G. y Stehberg, R. (2011). La «Estancia del gobernador» y Maipo-Mapocho: una hipótesis de legitimación de apropiación jurídica. Revista Chilena de Historia del Derecho, 23, 171-191.

Stehberg, R. y Sotomayor, G. (2012). Mapocho incaico. Boletín del Museo Nacional de Historia Natural, 61, 85-149.

Uribe, M. y Sánchez, R. (2016). Los incas en Chile. Aportes de la arqueología chilena a la historia del Tawantinsuyu (ca. 1400 a 1536 años d. C.) En F. Falabella, M. Uribe, L. Sanhueza, C. Aldunate y J. Hidalgo (Eds), Prehistoria en Chile. Desde sus primeros habitantes hasta los incas (pp. 529-572). Editorial Universitaria.

Valdivia, P. de (1929 [1500-1554]). Cartas que tratan del descubrimiento y conquista de Chile. Establecimiento Tipográfico de M. Carmona. Sevilla. http://www.memoriachilena.gob.cl/602/w3-article-8174.html 